\section{Safety Regulations for Alcohol Storage in Laboratories}

Patrick Brooks, Naiad Technologies, Inc.

Questions keep arising regarding safety regulations for storage of alcohol and other flammable liquids in a laboratory. I hope what follows sheds some light on this issue.

Ethanol is classified as a Class IB combustible liquid. Class IB liquids have a maximum allowable container capacity of 20 liters in "metal (non-DOT approved) or approved plastic containers, safety cans or DOT specification metal drums."

The amount of combustible liquids allowable is determined by the size of the "laboratory unit". For hospitals with sprinkler systems, per 100 square feet of laboratory space, Class I, II and IIIA (including IB) flammable liquids are limited to $4 \mathrm{~L}$ (1.1 gallons) not in approved storage containers or safety cans and $7.5 \mathrm{~L}$ ( 2 gallons) total, including quantities in storage cabinets and safety cans. That is, only half of the combustibles in a lab can be outside of approved storage containers. Note that there is no rule governing total volume except as it pertains to lab area and to container size.

The key definition here is "laboratory unit". Some Environmental Health \& Safety Officers define "laboratory unit" roughly as the space enclosed by fire doors. Thus, for all but the smallest hospitals and laboratories, there should be few restrictions because of space-related alcohol volume limitations. As an example, one Sakura VIP tissue processor has $21 \mathrm{~L}$ of ethanol and $9 \mathrm{~L}$ of Xylene (Class IIIA). Assuming that a tissue processor is not an approved storage container, this means that the "lab unit" would need to be a minimum of $750 \mathrm{sq}$. ft. ( $30 \times 25 \mathrm{ft}$ ) for each tissue processor to be "legal" [( 30 L/ 4 L) X 100 sq. ft.].

For a tissue processor that is considered to be an approved storage container, then the space requirements are halved.

The codes are very specific about volume of flammable liquids. When specifying volumes of flammable liquids, they indicate that "...the total volume of Class I liquids outside of approved storage cabinets and safety cans shall not exceed..." The word "shall" is a mandatory requirement - it does not mean "may."

Note that the hospital laboratories have stricter rules than other laboratories for the amount of combustible liquids they may have. The NFPA regulations spell this out quite succinctly. Educational institution laboratories are more stringent, as are commercial laboratories, but neither are not as stringent as hospital laboratories.

References from the National Fire Protection Association, a national body whose rules are generally adopted.

NFPA 45 Standard on Fire Protection for Laboratories Using Chemicals, 1996 Edition. Particularly key is Table 2-2(a) on pg. 45-7. Container size restrictions are referenced in Table 7-2 pg. 45-16.

NFPA 30 Flammable and Combustible liquids Code, 1996 Edition. Container size restrictions are referenced in Table $4.2 .3 \mathrm{pg}$. 30-32.

NFPA 497 Recommended Practice for the Classification of Flammable Liquids, Gases, or Vapors and Hazardous (Classified) locations for Electrical Installations in chemical Process Areas

NFPA 99 Standard for Health Care Facilities. Particularly key are paragraphs 10-7.2.1 and 10-7.2.2.

The NFPA is not necessarily the last word on this subject. The Universal Fire Code also addresses this topic and its use as a standard is more prevalent on the West Coast - the NFPA is more of an Eastern US standard. Moreover, individual states may enact their own more stringent regulations above even these. California for instance, and L.A. in particular, have different regulations.

Xenton Vacuum Homepage - Netscape

Back Forvard Reload Home Search Guide Print Security Stop Netscape

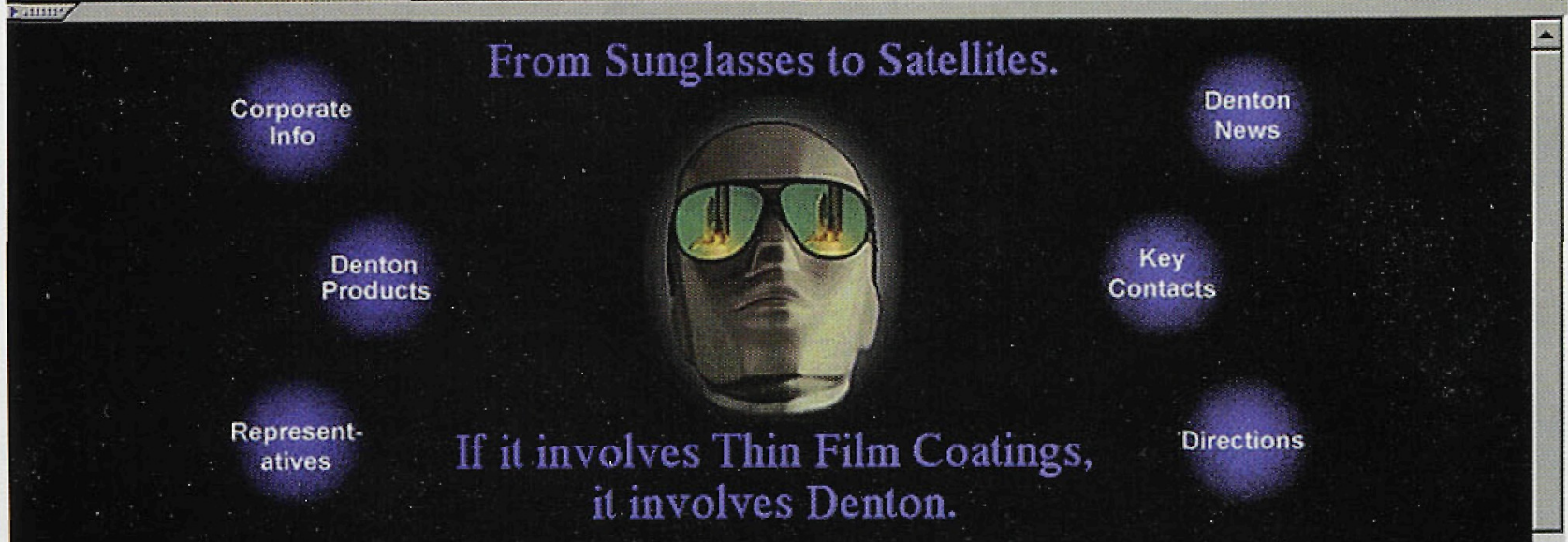

http://www.dentonvacuum.com

Desk II Cold Sputtercoater | DV 502A Carbon Coater | DV 401 Desktop Carbon Coater HI RES 100 High Resolution Chromium Coater | DCP-1 Critical Point Dryer Desk II TSC Turbo Sputter Coater | BTT III Benchtop Carbon Coater 